\title{
A valorização da sociobiodiversidade na alimentação escolar
}

\author{
Tayrine Parreira Brito ${ }^{1}$, Luiz Carlos Dias da Rocha², Aloísia Rodrigues Hirata ${ }^{3}$, Rogério \\ Robs Fanti Raimundo e Lívia Oliveira Galvão ${ }^{5}$
}

O objetivo do trabalho foi investigar a realidade da inserção dos alimentos da sóciobiodiversidade na alimentação escolar das escolas públicas do estado de Minas Gerais e sua relação com as questões ambientais. Tratou-se de uma pesquisa documental de abordagem qualitativa e os materiais de investigação foram as sistematizações elaboradas pelo Centro Colaborador em Alimentação e Nutrição Escolar do Instituto Federal do Sul de Minas Gerais (CECANE IFSULDEMINAS) no produto das Oficinas Regionais realizadas em 2018. As oficinas foram realizadas em diferentes regiões do estado, nos municípios de Lavras, Boa Esperança, Bambuí, Uberlândia e Pompéu. Foi constatado um total de 73 itens alimentares diferentes, destes 15 são considerados nativos dos biomas brasileiros e seis Plantas Alimentícias Não Convencionais (PANCs). O resultado do levantamento feito nas oficinas demonstrou pouca diversidade alimentar nos cardápios escolares, sendo que 26 itens foram citados em todas oficinas. Este padrão alimentar é preocupante do ponto de vista ambiental, uma vez que está restrito a poucas espécies de plantas. Por outro lado, o Brasil é um país de grande riqueza biológica, com muitas espécies consideradas propícias para a alimentação humana, onde a simbiose entre homem e natureza acontece nos processos de sociobiodiversidade, um potencial a ser valorizado, em que a escola aparece como um mecanismo estratégico de incentivo.

Palavras-chave: Educação Alimentar e Nutricional; Biodiversidade; Costumes Alimentares; PANCs.

\section{The valorization of sociobiodiversity in school meals}

The objective of the work was to investigate the reality of the inclusion of socio-biodiversity meals in the school public schools in the state of Minas Gerais and its relations with environmental issues. The study was documentary research with a qualitative approach and the materials of investigation were systematizations developed by CECANE IFSULDEMINAS in the product of the Regional Workshops held in 2018. The workshops were held in different regions of the state, in the municipalities of Lavras, Boa Esperança, Bambuí, Uberlândia and Pompéu. A total of 73 different food items were found, of which 15 are considered to be native to Brazilian biomes and 6 non-conventional food plants (NCFPs). The result of the survey carried out in the workshops showed little meals diversity in the school menus, with 26 items being cited in all workshops. This dietary pattern is worrysome from

\footnotetext{
${ }^{1}$ Doutoranda na Faculdade de Engenharia Agrícola da Universidade Estadual de Campinas - UNICAMP. Endereço para correspondência: Rua Sargento Mor Toledo Pizza, 413, Centro, Inconfidentes - MG. CEP: 37576-000. Telefone (35) 9 9908-9051. E-mail: tayrinepb@gmail.com

2 Professor no Instituto Federal do Sul de Minas Gerais - Campus Inconfidentes.

${ }^{3}$ Doutoranda na Faculdade de Engenharia Agrícola da Universidade Estadual de Campinas - UNICAMP e servidora no Instituto Federal do Sul de Minas Gerais.

${ }^{4}$ Servidor do Instituto Federal do Sul de Minas Gerais - Campus Inconfidentes e coordenador do Centro Colaborador em Alimentação e Nutrição Escolar do Instituto Federal do Sul de Minas Gerais.

${ }^{5}$ Agente nutricionista no Centro Colaborador em Alimentação e Nutrição Escolar do Instituto Federal do Sul de Minas Gerais.
} 
an environmental point of view, since it's restricted to few plant species. On the other hand, Brazil is a country of great biological wealth, with many species considered suitable for human consumption, where the symbiosis between man and nature occurs in the processes of socio-biodiversity, a potential to be valued, where schools appears as a strategic mechanism to encourage it.

Keywords: Food and Nutrition Education; Biodiversity; Food Customs; NCFPs.

\section{INTRODUÇÃO}

A alimentação escolar é um tema mundial dado que atualmente cerca de 169 países oferecem ao menos uma refeição diária em suas escolas [1]. O Brasil é o segundo país com maior número de estudantes beneficiados com a alimentação escolar. Segundo o Fundo Nacional de Desenvolvimento da Educação (FNDE) são cerca de 40 milhões de estudantes, em primeiro está a Índia com 114 milhões e em terceiro os Estados Unidos com 45 milhões [1]. A garantia da alimentação nas escolas públicas é uma maneira de contribuir para permanência dos estudantes (crianças e adolescentes) nas escolas, apoiando o desenvolvimento estudantil e fomentando a melhoria das habilidades cognitivas [1]. Um estudante com fome, certamente não alcançará o mesmo rendimento de aprendizagem que teria se estivesse alimentado.

No Brasil a alimentação escolar vem sendo aperfeiçoada e todas as refeições que são hoje servidas nas escolas públicas devem ser prescritas por um nutricionista responsável, que deverá elaborar um cardápio balanceado conforme as necessidades nutricionais dos estudantes. Além disso, o cardápio deve considerar também os hábitos alimentares locais.

Com vistas a continuidade no atendimento aos discentes e buscando uma menor interferência nos costumes alimentares regionais, a partir da publicação da Lei 11.947/2009 todas as escolas públicas devem usar no mínimo 30\% do recurso suplementar que recebem do governo federal para a alimentação na aquisição de alimentos direto da agricultura familiar prioritariamente local ou regional [2]. Vale ressaltar, que os hábitos alimentares estão geralmente relacionados aos recursos disponíveis nas regiões, ou seja, a espécies de plantas nativas e também ao que é produzido local e regionalmente.
No último século, houve mudanças expressivas sobre a diversidade alimentar, acredita-se que o número de plantas consumidas pelo ser humano caiu de 10 mil para 170 nos últimos cem anos [3]. De acordo com Kelen et al. [4] só no Brasil existem "pelo menos 3 mil espécies de plantas alimentícias com ocorrência. Estima-se que no país pelo menos $10 \%$ da flora nativa (4 a 5 mil espécies de plantas) sejam alimentícias". Entretanto, embora haja esta diversidade, são poucas as plantas nativas presentes na alimentação diária dos brasileiros.

No trabalho realizado por Monego et al. [5] sobre a inserção de frutas e frutos nativos do cerrado na alimentação escolar, os autores chegaram à conclusão de que ambos possuem potencial, porém encontram-se subaproveitados e mal explorados comercialmente. $\mathrm{O}$ mesmo foi indicado por Guimarães et al. ${ }^{\left[{ }^{[6]}\right.}$ sobre as preparações regionais. Os autores inidicaram que ainda é deficiente a inclusão deste tipo de preparo nos cardápios escolares.

Buscando oportunizar espaço de valorização da cultura alimentar, a Resolução 26/2013 do Fundo Nacional de Desenvolvimento da Educação (FNDE)

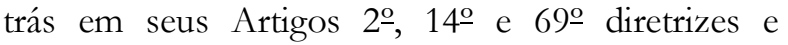
deliberações da alimentação escolar como apoio ao desenvolvimento sustentável, com a aquisição de alimentos diversificados da agricultura familiar e de povos tradicionais $[7]$.

Esta valorização e o reconhecimento da sociobiodiversidade aparece como uma necessidade, de modo que fortaleça a relação simbiótica entre as comunidades rurais tradicionais com a natureza, criando condições para a reprodução dos conhecimentos construídos historicamente pela oralidade passada entre gerações e também para a preservação dos recursos naturais ${ }^{[8]}$.

Neste sentido, o objetivo do presente trabalho é verificar se os alimentos da 
sóciobiodiversidade brasileira têm sido inseridos na alimentação servida nas escolas públicas do estado de Minas Gerais e sua relação com as questões ambientais.

\section{Contexto da Sociobiodiversidade Brasileira}

O Brasil ganhou lugar de destaque nas pesquisas sobre biodiversidade, devido a grande diversidade biológica que o país apresenta [8]. De acordo com o extinto Ministério do Desenvolvimento Agrário (MDA) [9] O Brasil juntamente com outros 20 países, possuem $70 \%$ da biodiversidade do planeta Terra, em apenas 10\% de superfície.

Existem no Brasil seis biomas recorrentes (Mata Atlântica, Cerrado, Amazônia, Pantanal, Caatinga e Pampa) que conforme o Plano Nacional de Promoção das Cadeias de Produtos da Sociobiodiversidade (PNPSB) possuem uma exuberante riqueza biológica associada "a uma grande diversidade sociocultural, representada por mais de 200 povos indígenas e por inúmeras comunidades tradicionais (quilombolas, extrativistas, pescadores, agricultores familiares)" ${ }^{[10] .}$

Estes povos e comunidades construíram e constroem suas vidas ao entorno da disposição dos recursos naturais e por isso são detentores do conhecimento e das habilidades de convívio e manejo da biodiversidade [8]. No PNPSB [10] foi definido sociobiodiversidade como um "conceito que expressa a inter-relação entre a diversidade biológica e a diversidade de sistemas socioculturais".

O PNPSB e a Lei no 11.947 foram publicados no mesmo ano, e enquanto o primeiro buscou fortalecer a cadeia produtiva da sociobiodiversidade, tendo de acordo com Moura Fé e Gomes [8] como uma de suas diretrizes o aproveitamento "do manejo sustentável de áreas naturais por comunidades tradicionais para a efetivação de cadeias produtivas, visando à sua incorporação ao mercado", o segundo abriu a possibilidade de um canal de comercialização, priorizado a compra dos alimentos para as escolas diretamente dos agricultores familiares e povos tradicionais.
Observa-se a existência de uma preocupação com a biodiversidade e a tentativa de valorização. Segundo Silva e Castro [11] a conservação dos recursos naturais "figura entre as principais preocupações em termos mundiais, frente à ameaça da extinção de espécies e o possível colapso dos ecossistemas, devido à interdependência entre os elementos existentes nas florestas".

No país existem pelo menos 3 mil espécies de plantas alimentícias com ocorrência [4]. Contudo são poucas as que compõem a dieta diária dos brasileiros. De acordo com o Guia Alimentar elaborado pelo Ministério da Saúdee ${ }^{[12]}$,

$$
\begin{aligned}
& \text { [...] frutas, legumes e } \\
& \text { verduras, originários do } \\
& \text { Brasil, não são } \\
& \text { comercializados } \\
& \text { nacionalmente em } \\
& \text { supermercados e estão } \\
& \text { presentes, } \\
& \text { preponderantemente, em } \\
& \text { redes locais, muitas vezes } \\
& \text { apenas em sistemas } \\
& \text { informais de varejo. }
\end{aligned}
$$

Diante deste contexto, em 2016 os ministérios do Meio Ambiente e de Desenvolvimento Social publicaram a Portaria Interministerial no 163/2016, que teve por objetivo listar as espécies nativas da flora brasileira que devem fazer parte das aquisições dos mercados institucionais ${ }^{[13]}$.

A lista contou com 63 espécies que podem ser encontradas em diferentes regiões do país e que poderiam ser incluídas na alimentação escolar.

[...] açaí, açaí solteiro, araticum/pana, araçá, araçáboi, araçá-pera, aroeirapimenteira, arumbeva, babaçu, bacaba, bacuri, baru/cumbaru, beldroega, buriti, butiá, cagaita, caju, caju-do-cerrado, camucamu, cara-amazônico, castanha do Brasil/castanha do Pará cereja, chichá, coquinho-azedo,

crem/batata crem, croá, cubiu, cupuaçu, erva mate, fisalis, goiaba-serrana, 
guabiroba, guabirova, gueroba, jabuticaba, jaracatiá/mamãozinho, jaracatiá/mamão do mato, jatobá, jenipapo, juçara, jurubeba, licuri, macaúba, major-gomes, mandacaru, mangaba, mangarito, maracujá, min-pepininho, murici, ora-pro-nobis, patuá, pequi, pêra-do-cerrado, pinhão, pitanga, pupunha, taioba, taioba-roxa, tucuma, umari, umbu, umbucajá/taperebá, urucum e uvaia [13].

Neste trabalho foram considerados alimentos da sóciobiodiversidade aqueles provenientes de espécies de plantas nativas dos biomas brasileiros, as plantas alimentícias não convencionais (PANCs) e as preparações típicas regionais.

Entende-se por planta nativa aquela que é "naturalmente própria da região em que vive, ou seja, que cresce dentro dos seus limites naturais incluindo a sua área potencial de dispersão" [14]. E as PANCs são plantas alimentícias que se desenvolvem em ambientes naturais sem a necessidade de insumos e da derrubada de novas áreas [15]. Os preparos típicos ou a gastronomia típica é de acordo com Muller e Fialho [16] "entendida neste contexto, como aquela que identifica uma localidade, dentro de um processo históricocultural". Foram a partir destes conceitos que descreveu-se a discussão ao entorno dos alimentos da sóciobiodiversidade.

\section{PROCEDIMENTO METODOLÓGICO}

Trata-se de uma pesquisa documental de abordagem qualitativa. Os documentos investigados foram as sistematizações e relatórios de cincos oficinas realizadas pelo Centro Colaborador em Alimentação e Nutricional Escolar (CECANE) do Instituto Federal do Sul de Minas Gerais (IFSULDEMINAS) com sede no Campus Inconfidentes. As oficinas foram realizadas no ano de 2018 em quatro regiões do estado de Minas Gerais (Uberlândia no Triângulo Mineiro, Pompéu na Central Mineira, Boa Esperança no Sul de Minas Gerais, Lavras no Sul de Minas Gerais/Campo das Vertentes e Bambuí no Oeste de Minas) (Figura 1).
Figura 1 - Mapa das regiões do estado de Minas Gerais em que as oficinas foram realizadas

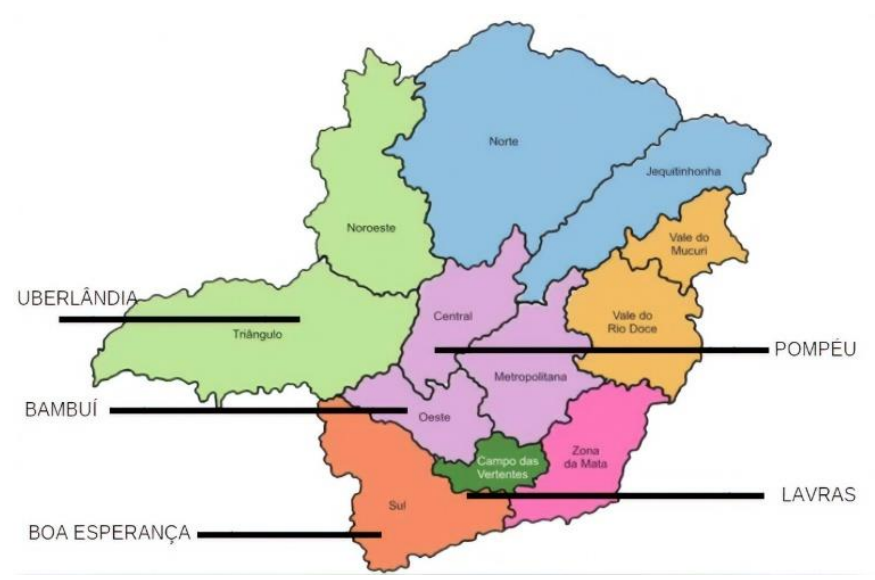

Fonte: Adaptado de SINDOJUS/MG, 2013 [17].

Cada oficina contou com a participação média de seis municípios de entorno somando no total das cinco oficinas a participação de 34 municípios, representados por 45 nutricionistas, 45 extensionistas rurais, 20 diretores de escolas estaduais e gestores municipais, 13 representantes dos Conselhos de Alimentação Escolar (CAE) e 100 agricultores familiares. A listagem dos municípios e do número de atores por categoria pode ser observada no quadro em anexo a este trabalho.

Durante a realização das oficinas, foram levantadas as demandas de alimentos das escolas e a oferta de alimentos dos agricultores familiares. E por meio do levantamento foi possível verificar se nas demandas da alimentação escolar estavam incluídos alimentos nativos, PANCs e preparos típicos para a alimentação escolar.

Vale ressaltar que o trabalho se refere apenas aos alimentos de origem vegetal e que os nomes utilizados para identificação dos mesmos são populares, atribuídos pelas pessoas que estiveram presentes na oficina. Outro fato a ser ressaltado é que não foram utilizadas fontes secundárias como cardápios escolares, projetos de venda dos agricultores e chamadas públicas. 


\section{RESULTADOS}

O estado de Minas Gerais é composto por três biomas: Cerrado (57\%), Mata Atlântica (41\%) e Caatinga ( $2 \%)$. As regiões onde ocorreram as oficinas do CECANE estão localizadas nos biomas: Cerrado - Uberlândia, Pompéu e Bambuí, e áreas de transição da Mata Atlântica para o Cerrado - Boa Esperança e Lavras (Figura 2). As oficinas tiveram por objetivo promover a articulação entres os atores do PNAE, relacionando os alimentos que são demandados para compor o cardápio escolar e os alimentos que são ofertados pela produção dos agricultores familiares, buscando identificar os desencontros entre demanda e oferta.
Figura 2 - Biomas do estado de Minas Gerais onde foram realizas as oficinas

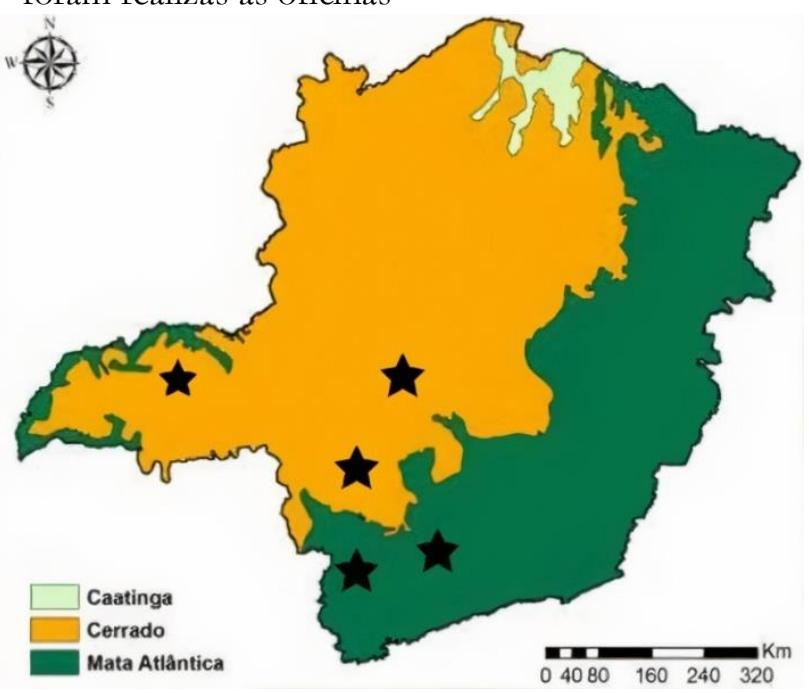

Fonte: Adaptado de Enciclopédia Global, 2018 [18].

Nas cinco oficinas foi indicada a demanda total de 63 itens alimentares distintos, mas em nenhuma das oficinas a demanda atingiu este valor (Tabela 1). Pode-se considerar uma diversidade pequena quando comparada a abrangência de plantas comestíveis que o Brasil possui e que a própria agricultura familiar apresentou nas oficinas como oferta.

Tabela 1 - Itens alimentares demandados pelas entidades executoras nas oficinas do CECANE IFSULDEMINAS em 2018.

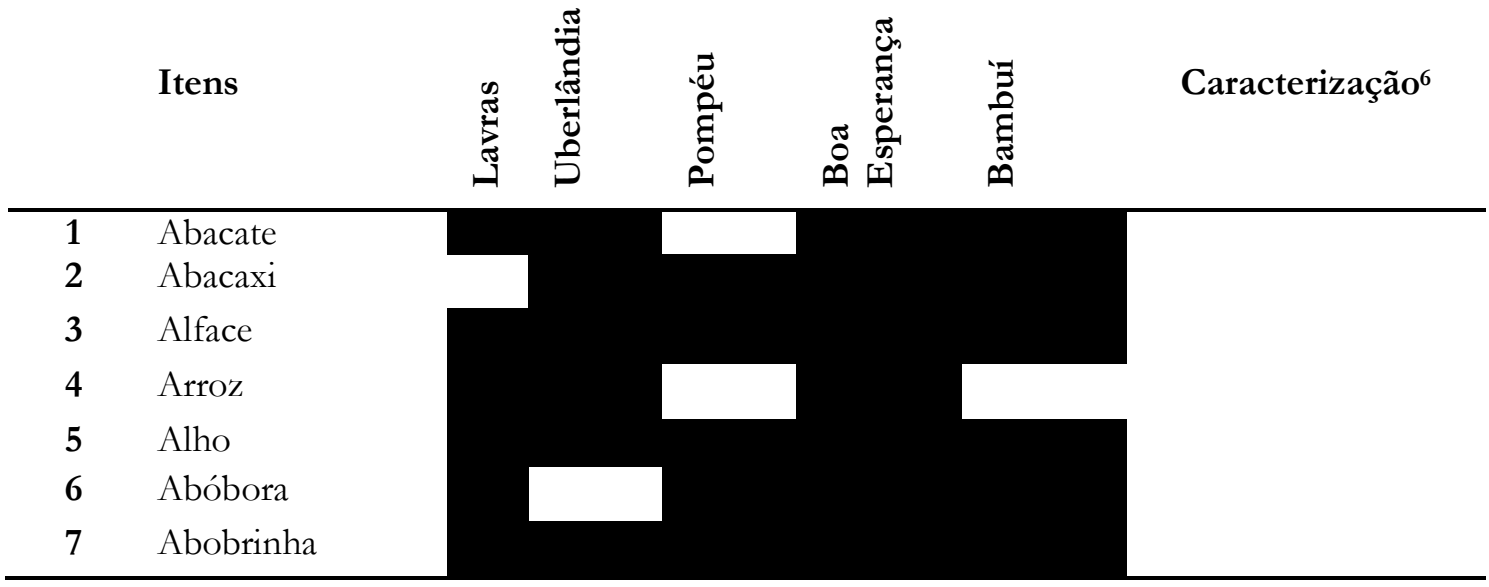

${ }^{6}$ A classificação foi fundamentada na Portaria Interministerial nำ163/2016, na 2 $2^{\mathrm{a}}$ Edição do Catálogo de Produtos da Sóciobiodiversidade do Brasil e no trabalho de Barreira et al. (2015). 


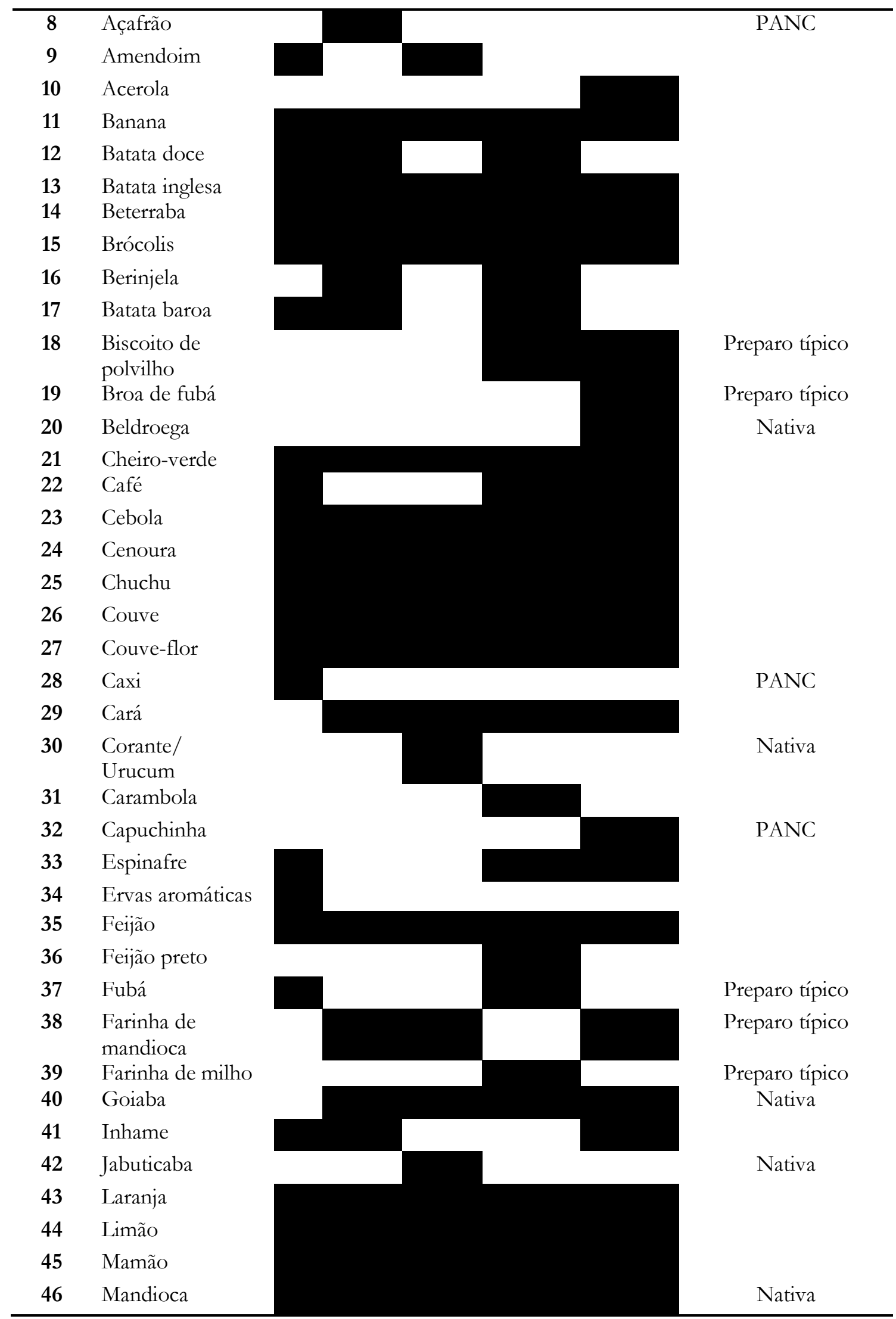


A valorização da sociobiodiversidade na alimentação escolar. Brito et al.

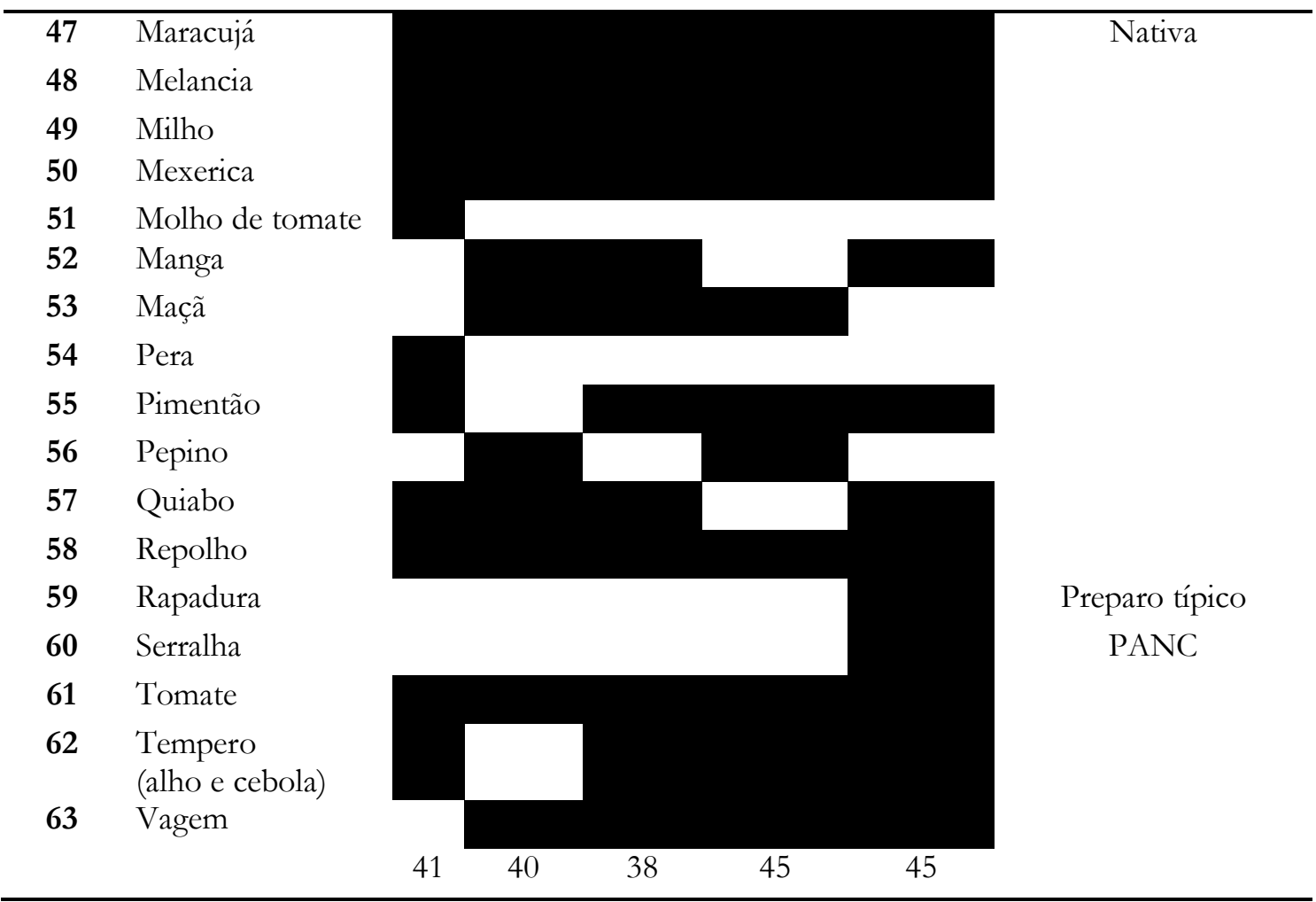

Fonte: Organização dos autores, 2020.

Houve alimentos que se repetiram durante as oficinas, tanto no levantamento da demanda quanto da oferta. Do total de itens que foram demandados 24 apareceram em todas as oficinas, sendo eles também os itens mais comprados pelas escolas em termos de quantidade (batata, banana, cenoura, alface, feijão, tomate e etc) indicando a existência de uma padronização dos cardápios escolares.

Na tabela 1 é possível verificar que dos 63 itens que foram demandados, 16 são alimentos considerados da sóciobiodiversidade, aparecendo grande parte em apenas uma oficina. A mandioca e o maracujá foram os únicos alimentos nativos indicados como demanda em todas as oficinas, possivelmente por serem alimentos que estão inseridos no mercado de uma forma geral, em todas as regiões do país.
A oferta de alimentos apresentada pelos agricultores familiares quase sempre apareceu maior do que a demanda. Na oficina no município de Lavras foram 46 itens ofertados, em Uberlândia foram 56, em Pompéu 95, em Boa Esperança 54 e em Bambuí 92. A soma dos diferentes itens ofertados pela agricultura familiar nas oficinas totalizaram 140 alimentos, ou seja, mais que o dobro da soma do que foi demandado. Destes, 42 são alimentos considerados da sóciobiodiversidade, sendo 22 nativos, 10 PANCs e 10 preparos típicos confome disposto na figura 3. 
Figura 3 - Alimentos nativos, PANCs e preparos típicos ofertados pelos agricultores nas oficinas do CECANE IFSULDEMINAS

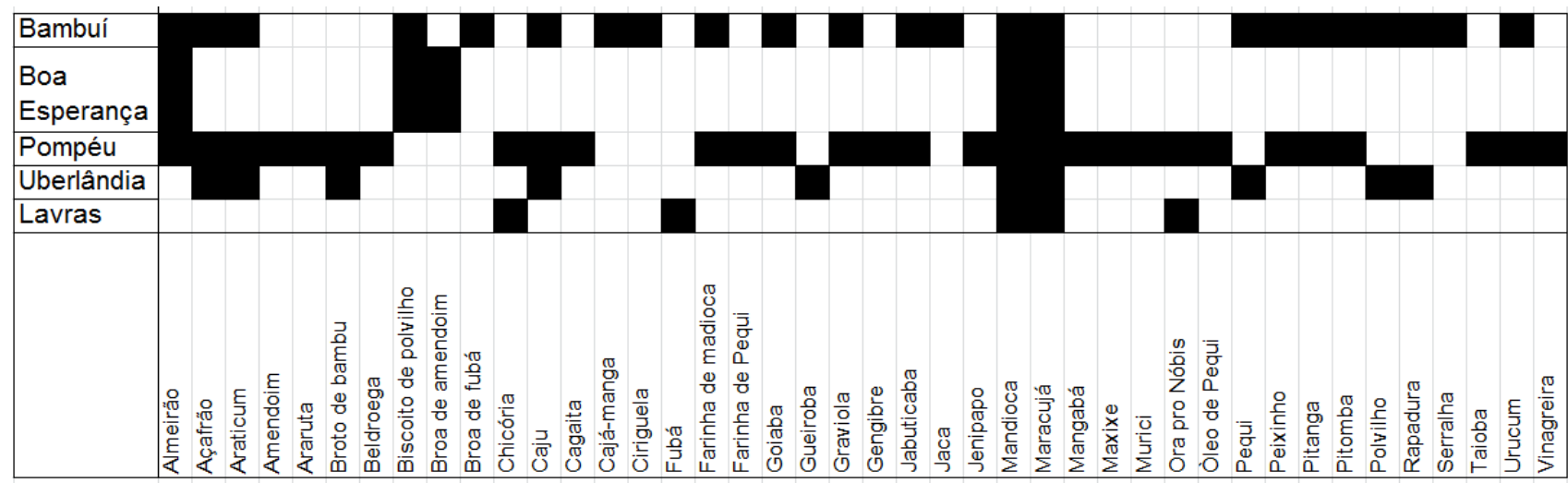

Fonte: Organização dos autores, 2020.

Vale ressaltar que nos municípios de Pompéu e Bambuí onde foi apresentada a maior diversidade de alimentos ofertados pelos agricultores, são municípios que tem em seus territórios comunidades tradicionais (quilombolas e indígenas) e também assentamentos de reforma agrária, reforçando a importância destes povos para a conservação da biodiversidade. Este fato chama também a atenção para a contradição, pois os nutricionistas e gestores de Pompéu e Bambuí não demandaram de nenhum alimento nativo do bioma cerrado onde estão localizados, embora os agricultores tenham indicado produção e oferta.

Sobre os preparos típicos, grande parte do que foi oferecido pelos agricultores é possível de ser encontrado por todo o país nas grandes redes de mercado, no entanto a de se considerar que quando esses alimentos são produzidos por agricultores familiares e povos tradicionais, eles são processados de modo diferente do industrial, por exemplo, as farinhas são feitas manualmente geralmente por mulheres, o fubá é feito no moinho de pedra tocado por água. São preparações dotadas de conhecimentos e técnicas passadas por gerações.

Nesse sentido, evidencia-se o potencial produtivo dos agricultores familiares e a diversidade na produção, manejo e preparos dos alimentos da sóciobiodiversidade demonstrada na figura 3. Quinze alimentos que foram ofertados pelos agricultores nas oficinas estão na lista da Portaria Interministerial $n^{\circ}$
163/2016 citada anteriormente neste trabalho. Alguns deles como a araruta, o araticum, a jabuticaba, o pequi e a pitanga são espécies indicadas com risco de extinção pelo MMA[19]. São alimentos potenciais para composição dos cardápios escolares, proporcionando diversidade a alimentação escolar e valorizando os costumes e hábitos alimentares locais.

\section{DISCUSSÃO}

O padrão alimentar observado nas demandas que foram apresentadas nas oficinas do CECANE IFSULDEMINAS, corresponde a um modelo hegemônico de produção agrícola pautado na monocultura, baseado mundialmente em poucas espécies de plantas e o qual tem gerado danos irreversíveis aos recursos naturais [20]. Cerca de 70\% da produção mundial atual é representada pelo milho, soja, arroz e trigo e os $30 \%$ restantes para os demais cultivos como feijão, mandioca, hortaliças e frutas [3]. No Brasil denominou-se por agronegócio este tipo de produção, onde a grande parte do que se é produzido no país é exportado. Para Weber [21] "O agronegócio hegemoniza a produção agrícola e impacta a biodiversidade, importando uma dura realidade sobre a questão alimentar e a fome no mundo".

A homogeneização dos hábitos alimentares é algo preocupante tanto do ponto de vista da segurança alimentar e nutricional, quanto também da perspectiva da preservação ambiental. Algumas das consequências para a saúde humana são conhecidas como: "a incidência de sobrepeso, de doenças não 
transmissíveis como diabetes, hipertensão, cânceres, artrites, cardiopatias e tantas outras doenças causadas por práticas alimentares inadequadas"[22]. Assim como também as consequências para o meio ambiente como: o desmatamento e a contaminação do solo, da água e do ar. Segundo Durazzo[23] "a nutrição e a sustentabilidade ambiental estão estreitamente ligadas ao sistema agroalimentar".

Frente a esta situação as práticas da agricultura familiar apresentam uma maior e mais significativa sustentabilidade na relação com os recursos naturais, sendo consideradas "como uma das melhores formas de uso e ocupação dos solos agrícolas, não somente pela possibilidade de geração de emprego e renda, mas também por demonstrar cuidados maiores com a biodiversidade, solos e rios"[24].

Quanto mais sustentável é a agricultura, mais ela é capaz de promover a proteção da saúde humana, o bem-estar animal e a conservação do meio ambiente, levando o alimento produzido a obter melhor qualidade e segurança[23]. Os agricultores familiares e os povos tradicionais têm nesse sentido contribuido efetivamente para a segurança alimentar e nutricional nos países considerados em desenvolvimento, como o Brasil[24]. De acordo Jonhs et al.[24] a produção destes agricultores são para abastecer a população local, regional e nacional, melhoram e diversificam as dietas tornando-as mais nutritivas, e ainda "satisfazem as preferências por uma variedade de alimentos culturalmente valiosos e sustentam padrões alimentares saudáveis enraizados nos ecossistemas regionais e práticas comunitárias".

Os hábitos são socialmente construídos, desta forma um hábito alimentar é definido a partir da disponibilidade e das escolhas alimentares. Nas escolas públicas brasileiras esta escolha é feita pela nutricionista responsável e pelas merendeiras responsáveis pelo preparo das refeições servidas nas escolas [25] [20]. O papel da escola é, portanto, crucial na educação alimentar e nutricional dos estudantes.

Os resultados apresentados demonstram que as escolas públicas de Minas Gerais têm reproduzido um padrão alimentar, tendo um cardápio homogêneo em regiões distintas ao mesmo tempo que há produção disponível para a inserção dos alimentos da sóciobiodiversidade na alimentação escolar. Girardi et al.[26] fizeram provocações importantes para o avanço da presença dos alimentos da sóciobiodiversidade nos cardápios escolares. Para as autoras é necessária a conscientização e capacitação dos profissionais e gestores envolvidos na alimentação escolar, além da destinação de recursos exclusivos para as aquisições de alimentos da sóciobiodiversidade e por fim, de um maior monitoramento e cobrança do FNDE acerca da aquisição desses produtos.

Para tanto, em âmbito local é necessário que os gestores criem estratégias para viabilizar a inserção de frutos nativos, PANCs e preparos regionais na alimentação escolar criando programa e projetos específicos de fomento[21]. E realizando também estudos de diagnóstico da biodiversidade local e do pontecial produtivo e agroecológico dos agricultores familiares.

$\mathrm{Na}$ pesquisa desenvolvida por Bosco e Domingos ${ }^{[27]}$ os autores revelaram o potencial do buriti no estado de Tocantins, considerando que os agricultores precisam de meios que facilitem a coleta, o armazenamento e a comercialização. Resultado este parecido com o que Monego et al. [5] tiveram nos estudos sobre a inserção de frutos do cerrado no cardápio escolar, onde o baru, buriti, cagaita, jatobá e pequi possuem potencial, mas são pouco explorados.

Outro exemplo que vale ser citado é a introdução do suco do fruto da juçara na alimentação escolar dos muncípios do litoral norte do estado de São Paulo. A juçara é uma palmeira nativa da Mata Atlântica conhecida pela extração do palmito, onde para retirá-lo é necessário sacrificar a ávore, por isso era uma espécie considerada em extinção. Com os estudos e testes sobre a utilização do fruto da juçara que é parecido com o açaí, foi desenvolvido projetos de utilização da polpa, e um deles foi servir o suco da polpa do fruto da juçara na alimentação escolar. O suco foi bem aceito pelos estudantes e os agricultores da região se organizaram em uma associação para fazerem de forma coletiva o beneficiamento e a comercialização da polpa[28][29]. Resumidamente houve uma troca entre o manejo predatório que era a extração do palmito para o manejo sustentável que é a extração dos frutos.

A introdução dos alimentos da sóciobiodiversidade na alimentação escolar é uma 
forma de valorizar o produto, possibilitando a geração de renda, a sustentabilidade e a utilização de práticas alimentares que respeite e resgate a identidade cultural das comunidades [5]. Monego et al. afirmam ainda que "é possível, também, que este incentivo promova formas de uso mais sustentáveis dos recursos naturais dos biomas, evitando as práticas comuns no extrativismo predatório" [5].

Conforme o levantamento de dados do Instituto Nacional de Pesquisas Espaciais (INPE) no ano de 2018 o desmatamento no bioma cerrado, que é o que ocupa a maior área no estado de Minas Gerais, foi de $6.657 \mathrm{~km}^{2}[30]$. Acredita-se que uma das formas de diminuir o desmatamento não só no Cerrado, mas também nos demais biomas, é incentivar o manejo sustentável das espécies nativas dos biomas. E a alimentação escolar possui grande potencial para isso.

Sobre a presença do regionalismo no cardápio escolar, nas oficinas os preparos demandados pelas escolas foram as farinhas e as quitandas. A presente pesquisa não analisou $\mathrm{O}$ cardápio das escolas, por isso as análises que se referem as preparações ficaram limitadas.

As plantas alimentícias não convencionais (PANCs) demandadas nas oficinas foram a beldroega, o caxi, a capuchinha, a serralha e o açafrão, conforme exposto na tabela 1. Pode-se considerar pouco, comparado ao potencial dessas plantas e a recorrência natural das mesmas em áreas agricultáveis, como por exemplo, na pesquisa realizada por Barreira et al. [15], onde os autores identificaram 59 espécies de PANCs com potencial alimentício na zona rural de Viçosa - MG, por meio de entrevistas com 20 moradores de diferentes comunidades rurais do município.

\section{CONCLUSÃO}

A alimentação escolar constitui um mercado importante para a agricultura familiar e os estudantes também são beneficiados com o fornecimento de alimentos frescos e de qualidade, oriundos da agricultura familiar. Para tanto, a pesquisa indica que há desencontro sobre o que se é demandado pelos nutricionistas e gestores com o que é ofertado pelos agricultores. Este desencontro por sua vez é fruto da homogeinização dos cardápios escolares que são elaborados sem o levantamento prévio da produção local, e acaba consequentemente por impor aos agricultores a produção de alimentos que estão dentro de um padrão alimentar, contribuindo para o desmatamento e a extinção das plantas nativas, para a inclusão de plantas exóticas e mercadológicas.

Quanto a introdução de alimentos da sóciobiodiversidade, o ambiente escolar parece ser o local ideal de incentivo e resgate a alimentos e preparos que fazem parte da cultura local. Os autores que já discorreram sobre o tema apontam para a necessidade de uma maior atenção dos governantes sobre a inserção destes alimentos na alimentação escolar, especialmente criando estratégias capazes de viabilizar a produção, o armazenamento e a comercialização.

O outro desafio que se coloca é o conhecimento por parte das nutricionistas responsáveis técnicas pela alimentação servida nas escolas sobre os alimentos da sóciobiodiversidade e sua importância, de modo que sejam capazes de compreender a alimentação para além do componente nutricional. Verifica-se desafio parecido aos extensionistas rurais que também acabam por potencializar a produção dos alimentos convencionais já inseridos no mercado, não incentivando os agricultores familiares em cultivar, extrair e manejar os alimentos nativos e não convencionais.

Foram poucos os estudos encontrados que exploraram a inclusão de alimentos da sóciobiodiversidade na alimentação escolar, embora demonstrem ter um grande potencial, tanto do ponto de vista social e cultural, mas também ambiental e econômico. Desta maneira revela-se a necessidade da implementação de mais estudos, de modo que incentive a presença de frutos nativos nos cardápios escolares, valorizando e relação social e cultural dos povos com essas espécies.

\section{REFERÊNCIAS}

[1] Cesar JT, Valentim EA, Almeida CCB, Schieferdecker MEM, Schmidt ST. Alimentação Escolar no Brasil e Estados Unidos: uma revisão integrativa. Ciência \& Saúde Coletiva. 2018; 23(3):991-1007. 
[2] Brasil. Lei no 11.947, de 16 de junho de 2009. Dispõe sobre o atendimento da alimentação escolar e do Programa Dinheiro Direto na Escola aos alunos da educação básica [Internet]. Brasília, DF; 2009 [acesso em 2019 nov 11]. Disponível em: http://www.planalto.gov.br/ccivil_03/_Ato20072010/2009/Lei/L11947.htm

[3] Embrapa. Mais do que matos, elas são as plantas alimentícias não convencionais (PANCs) [Internet]. Rio de Janeiro; 2018. [acesso em 2019 dez 10]. Disponível em: https://www.embrapa.br/busca-de-noticias/-

/ noticia/33580014/mais-do-que-matos-elas-sao-as-

plantas-alimenticias-nao-convencionais-pancs.

[4] Kelen MB, Nouhuys IS, Kehl LC, Brack P, Silva DB. Plantas alimentícias não convencionais (PANCs): hortaliças espontâneas e nativas. Porto Alegre: UFRGS; 2015.

[5] Monego ET, Alexandre VP, Sousa LM, Martins KA, Rosa JQ, Souza PL, Assis JN. Produção e potencial agrícolas de alimentos destinados à alimentação escolar em Goiás e no Distrito Federal, na Região Centro-Oeste do Brasil. Revista Nutrição. 2013; 26(2):233-241.

[6] Guimarães EP, Marques JM, Silva LL, Cardoso CG. Regionalismo presente nos cardápios da alimentação escolar no município de Campinorte - Goiás. Revista Brasileira de Geografia Médica e da Saúde. 2019; 15(31):95-104. DOI http://dx.doi.org/DOI 10.14393/Hygeia153147097.

[7] Brasil. Ministério da Educação. Resolução no 26, de 17 de junho de 2013. Dispõe sobre o atendimento da alimentação escolar aos alunos da educação básica no âmbito do Programa Nacional de Alimentação Escolar PNAE. Diário Oficial da União. 2013 jun 17.

[8] Moura Fé EG, Gomes JMA. Territorialidade e sociobiodiversidade na configuração do espaço produtivo da comunidade Olho d'Àgua dos Negros no município de Esperantina - PI. Sociedade \& Natureza. 2015; 27(2):297308. DOI http://dx.doi.org/10.1590/1982451320150208 .

[9] Brasil. Ministério do Desenvolvimento Agrário. A sociobiodiversidade brasileira [Internet]. Brasília, DF; 2018 [acesso em 2019 nov 11] Disponível em: http://www.mda.gov.br/sitemda/secretaria/saf-

biodiv/sociobiodiversidade-brasileira

[10] Brasil. Plano Nacional de Promoção das Cadeias Produtos da Sociobiodiversidade - PNBSB [Internet]. Brasília, DF; 2009 [acesso em 2019 nov 11]. Disponível em:

http://www.mda.gov.br/sitemda/sites/sitemda/files/us er_arquivos_64/PLANO_NACIONAL_DA_SOCIOBI ODIVERSIDADE-_julho-2009.pdf

[11] Silva IS, Castro EM. Interações rural-urbano: a sociobiodiversidade e o trabalho em portos, feiras e mercados de Belém, Pará. Novos Cadernos NAEA. 2013; 16(1):109-126.

[12] Brasil. Ministério da Saúde. Secretaria de Atenção à Saúde. Departamento de Atenção Básica. Guia alimentar para a população brasileira. 2.ed. Brasília: Ministério da Saúde; 2014.

[13] Brasil. Portaria Interministerial no 163/2016 [nternet]. Brasília, DF; 2016 [acesso em 2019 dez 14]. Disponível em: http://www.mma.gov.br/images/noticias_arquivos/pdf /sociobio.pdf

[14] Instituto Ambiental do Paraná. Conceitos gerais sobre espécies [Internet]. Curitiba; 2020 [acesso em 2020 fev 01]. Disponível em: http://www.iap.pr.gov.br/pagina814.html

[15] Barreira TF, Paula Filho GX, Rodrigues VCC, Andrade FM, Santos RH, Pinheiro-Santana HM. Diversidade e equitabilidade de Plantas Alimentícias Não Convencionais na zona rural de Viçosa, Minas Gerais, Brasil. Rev. Bras. Pl. Med. 2015; 17(4):964-974.

[16] Muller SG, Fialho FAP. A preservação dos saberes, sabores e fazeres da gastronomia tradicional no Brasil. Revista Travessias. 2011; 5(1):176-187.

[17] Sindojus. Mapa das regiões do estado de Minas Gerais. [Internet]. 2013 [acesso em 2020 nov 13] Disponível em: https://www.sindojusmg.org.br/site/2013/10/30/inaug uracao-oficial-da-subsede-do-sindojusmg-e-assembleiasgerais/

[18] Enciclopédia Global. Mapa dos biomas de Minas Gerais [Internet]. 2018 [acesso em 2020 mar 12] Disponível em: http://klimanaturali.blogspot.com/2018/09/mapa-dosbiomas-de-minas-gerais.html

[19] Martinelli G, Avila Moraes M, Anderson F, Hieatt C. Livro vermelho da flora do Brasil. Ministério do Meio Ambiente. Rio de Janeiro: Andrea Jakobsson: Instituto de Pesquisas Jardim Botânico do Rio de Janeiro; 2013. 
[20] Oliveira Júnior CJF, Voigtel SDS, Nicolau SA, Aragaki S. Sociobiodiversidade e agricultura familiar em Joanópolis, SP, Brasil: potencial econômico da flora local. Hoehne. 2018;45(1):40-54. DOI http://dx.doi.org/10.1590/2236-8906-78/2017.

[21] Weber LD. Alimentos sustentáveis e a preservação da sociobiodiversidade: uma análise da informação ambiental digital em Santa Maria, RS [monografia]. Santa Maria: Universidade Federal de Santa Maria. 2017.

[22] Walter B, Siliprandi E. Hábitos Alimentares, Segurança e Soberania Alimentar. In: Vilarta R, Gustavo L, Gutierrez GL, Monteiro MI (orgs.). Qualidade de Vida: Evolução dos Conceitos e Práticas no Século XXI. Campinas: IPES; 2010. p. 187-196.

[23] Durazzio A. The Close Linkage between Nutrition and Environment through Biodiversity and Sustainability: Local Foods, Traditional Recipes and Sustainable Diets. Sustainability. 2019;11(10):2876. DOI https://doi.org/10.3390/su11102876.

[24] Jonhs T, Powell B, Maundu P, Eyzaguirre PB. Agricultural biodiversity as a link between traditional food systems and contemporary development, social integrity and ecological health. Science of Food and Agriculture. 2013; 93(14):3433-3442. DOI https://doiorg.ez88.periodicos.capes.gov.br/10.1002/jsfa.6351.

[25] Lima RS, Ferreira Neto JA, Farias RCP. Alimentação, comida e cultura: o exercício da comensalidade. Demetra. 2015; $10(3): 507-522$.
[26] Girardi MW, Fabri RK, Bianchini VU, Martinelli SS, Cavalli SB. Oferta de preparações culinárias e alimentos regionais e da sociobiodiversidade na alimentação escolar: um estudo na Região Sul do Brasil. Segurança Alimentar e Nutricional. 2018;29(3):29-44. DOI http://dx.doi.org/10.20396/san.v25i3.8652261.

[27] Bosco CS, Domingos RN. A utilização de frutos regionais na merenda escolar do município de Palmas TO: um estudo do buriti quanto componente enriquecedor. Agri-Environmental Sciences. 2015;1(2):Edição Especial - XXII Jornada de Iniciação Científica.

[28] Borges MG, Carvalho IS, Steil CA. A juçara vai à escola: aprendizagem entre pessoas, coisas e instituições. Horizontes Antropológicos. 2015;21(44):309-329. DOI http://dx.doi.org/10.1590/S0104-71832015000200013.

[29] Souza SE. Manejo de Euterpe edulis Mart. para produção de polpa de fruta: subsídios à conservação da biodiversidade e fortalecimento comunitário [tese]. Piracicaba: Escola Superior de Agricultura "Luiz de Queiroz"; 2015.

[30] Instituto Nacional de Pesquisa Espaciais - INPE. Desmatamento no Cerrado é de $6.657 \mathrm{~km}^{2}$ em 2018 [nternet]. São José dos Campos; 2018 [acesso em 2019 dez 12]. Disponível em: http://www.inpe.br/noticias/noticia.php?Cod_Noticia=49 75\&utm_source $=$ dlvr.it\&utm_medium $=$ facebook 


\section{ANEXO}

Anexo 1: Quadro dos municípios e atores participantes das oficinas7.

\begin{tabular}{|c|c|c|c|c|c|c|c|c|c|}
\hline Pólos & $\begin{array}{l}\text { Municípios } \\
\text { Participantes }\end{array}$ & Nut. & CAE & $\begin{array}{l}\text { Prof. } \\
\text { Gest. }\end{array}$ & Org. & AF & Ext & O.A. & $\begin{array}{l}\mathrm{N}^{\circ} \text { total } \\
\text { de atores }\end{array}$ \\
\hline \multirow{7}{*}{ Lavras/MG } & Lavras & 7 & 0 & 4 & 0 & 4 & 5 & 2 & 22 \\
\hline & Nazareno & 1 & 0 & 0 & 0 & 1 & 1 & 0 & 3 \\
\hline & Nepomuceno & 1 & 0 & 0 & 0 & 2 & 1 & 0 & 4 \\
\hline & Ijaci & 1 & 0 & 0 & 0 & 0 & 1 & 0 & 2 \\
\hline & Carmo da cachoeira & 1 & 0 & 0 & 0 & 2 & 1 & 0 & 4 \\
\hline & Sto. Antônio do Amparo & 1 & 0 & 0 & 0 & 1 & 1 & 0 & 3 \\
\hline & Perdões & 0 & 0 & 0 & 0 & 4 & 1 & 0 & 5 \\
\hline Subtotal: & 7 & 12 & 0 & 4 & 0 & 14 & 11 & 2 & Total: 43 \\
\hline \multirow{6}{*}{ Uberlândia/MG } & Uberlândia & 8 & 3 & 3 & 7 & 10 & 4 & 0 & 35 \\
\hline & Tupaciguara & 1 & 0 & 0 & 0 & 5 & 1 & 0 & 7 \\
\hline & Monte Alegre & 0 & 0 & 0 & 0 & 1 & 1 & 0 & 2 \\
\hline & Nova Ponte & 1 & 0 & 0 & 0 & 1 & 1 & 0 & 3 \\
\hline & Indianópolis & 1 & 0 & 0 & 0 & 4 & 0 & 0 & 5 \\
\hline & Romaria & 1 & 3 & 3 & 0 & 1 & 1 & 0 & 9 \\
\hline Subtotal: & 6 & 12 & 6 & 6 & 7 & 22 & 8 & 0 & Total: 61 \\
\hline \multirow{6}{*}{ Pompéu/MG } & Pompéu & 2 & 0 & 4 & 3 & 14 & 0 & 5 & 28 \\
\hline & Martinho campo & 1 & 0 & 1 & 0 & 1 & 3 & 0 & 6 \\
\hline & Papagaios & 1 & 1 & 0 & 0 & 2 & 2 & 0 & 6 \\
\hline & Abaeté & 1 & 0 & 0 & 0 & 0 & 1 & 0 & 2 \\
\hline & Bom Despacho & 1 & 1 & 0 & 0 & 1 & 1 & 3 & 7 \\
\hline & Curvelo & 0 & 0 & 0 & 0 & 0 & 0 & 1 & 1 \\
\hline Subtotal: & 6 & 6 & 2 & 5 & 3 & 18 & 7 & 9 & Total: 50 \\
\hline \multirow{7}{*}{$\begin{array}{c}\text { Boa } \\
\text { Esperança/MG }\end{array}$} & Aguanil & 1 & 0 & 0 & 0 & 2 & 1 & 0 & 4 \\
\hline & Santana da Vargem & 1 & 0 & 0 & 0 & 2 & 1 & 0 & 4 \\
\hline & Coqueiral & 1 & 0 & 0 & 0 & 3 & 1 & 0 & 5 \\
\hline & Campo Belo & 1 & 2 & 0 & 0 & 2 & 0 & 1 & 6 \\
\hline & Três Pontas & 1 & 1 & 0 & 0 & 2 & 1 & 0 & 5 \\
\hline & Cristais & 1 & 0 & 0 & 0 & 3 & 1 & 0 & 5 \\
\hline & Boa Esperança & 2 & 2 & 4 & 0 & 6 & 5 & 3 & 22 \\
\hline Subtotal: & 7 & 8 & 5 & 4 & 0 & 20 & 10 & 4 & Total: 51 \\
\hline \multirow{8}{*}{ Bambuí/MG } & Bambuí & 2 & 0 & 0 & 0 & 19 & 5 & 9 & 35 \\
\hline & Vargem Bonita & 1 & 0 & 0 & 0 & 1 & 0 & 0 & 2 \\
\hline & São Roque & 1 & 0 & 0 & 0 & 1 & 0 & 0 & 2 \\
\hline & Luz & 1 & 0 & 0 & 0 & 3 & 1 & 0 & 5 \\
\hline & Tapiraí & 1 & 0 & 0 & 0 & 2 & 1 & 0 & 4 \\
\hline & Córrego Danta & 1 & 0 & 0 & 0 & 0 & 1 & 0 & 2 \\
\hline & São Sebastião do Oeste & 0 & 0 & 0 & 0 & 0 & 1 & 0 & 1 \\
\hline & Divinópolis & 0 & 0 & 1 & 0 & 0 & 0 & 0 & 1 \\
\hline Subtotal: & 8 & 7 & 0 & 1 & 0 & 26 & 9 & 9 & Total: 52 \\
\hline TOTAL GERAL & 34 & 45 & 13 & 20 & 10 & 100 & 45 & 24 & 257 \\
\hline
\end{tabular}

Fonte: Adaptado do CECANE IFSULDEMINAS.

7 As categorias do quadro 1 são: Nut. - Nutricionista; CAE - Conselho de Alimentação Escolar; Prof. e Gest. - Profissionais da Educação e Gestores; Org. - Organizações da agricultura familiar, cooperativas e associações; AF - Agricultura Familiar; O.A. Outros Atores. 